\title{
CHARACTERIZING EMISSION AND BREATHING-ZONE \\ CONCENTRATIONS FOLLOWING EXPOSURE CASES TO FLUORORESIN- \\ BASED WATERPROOFING SPRAY MISTS
}

David S. Vernez, Pierre-Olivier Droz, Catherine Lazor-Blanchet, Sylvain Jaques

Institute of Occupational Health Sciences (IST), rue du Bugnon 19, 1005 Lausanne, Switzerland

number of words: 6616

* Corresponding author. Tel.: ++41 2131474 21; fax: ++41 2131474 20; e-mail: David.Vernez@inst.hospvd.ch 
CHARACTERIZING EMISSION AND BREATHING-ZONE

CONCENTRATIONS FOLLOWING EXPOSURE CASES TO FLUORORESIN-

BASED WATERPROOFING SPRAY MISTS 


\begin{abstract}
Measurements and simulations have been performed in order to assess the workers' exposure to solvent vapours and aerosols during the waterproofing of a tiled surface. This investigation followed two recent incidents in the same company, during which workers experienced acute respiratory illness after having sprayed a stain-repellent resin containing fluorinated polymers on stone-tiled walls and floors. As the waterproofing activity has been carried out during years in the tile company without encountering any exposure problems prior to these cases, it is strongly suspected that the incidents were linked to a recent change in the composition of the coating mixture. Experimental measurements and simulations indicated that the emission rate of particles smaller than $10 \mu \mathrm{m}$ may be estimated at $\mathbf{0 . 6 6} \mathbf{~ m g / s}(\mathrm{SD} 0.10)$ for the old resin and at $\mathbf{0 . 3 7} \mathbf{~ m g / s}$ (SD 0.04) for the new one. The measurement of the solvent emission rate from surfaces coated with the two resins indicated that, shortly after spraying, the emission was in a range of $\mathbf{1 8}$ to $20\left[\mathbf{m g} / \mathbf{s} \mathbf{m}^{2}\right]$ and was similar with both products. Solvent and overspray emission rates have been introduced in a two-zone compartment model. The results obtained in the near-field indicate significant exposure to overspray mist (7 and $\mathbf{3 4}\left[\mathbf{m g} / \mathbf{m}^{3}\right]$ for new resin) and important exposure to solvent vapours $(\mathbf{8 0}$ to $350 \mathbf{~ p p m}$ for the new resin). It is also shown that the introduction of the new resin tends to decrease significantly the levels of solvents and particulates in the workers' breathing zone. These results strongly suggest that cases of acute respiratory illness are related to the specific toxicity of the fluorinated polymer itself. The fact that the same polymer is used in various commercial products raises concern with regards to other possible occupational and domestic exposures.
\end{abstract}

Keywords: Aerosol eXPosure, Airborne Particles, WATERPRoOfing Spray, Tile-COATING, FLUORORESINS 


\section{INTRODUCTION}

Fluorinated polymers are widely used in a number of technologies requiring low surface energy, such as coating surface applications. The high electronegativity of fluorine strongly affects the molecules physical and chemical properties ${ }^{[1]}$. Amongst other effects, the presence of fluorine tends to reduce surface tension and increase thermal and chemical stability. fluoro-acrylate polymers, which exhibit a high stability and durability, are more and more frequently used in coating mixtures.

There is evidence that inhalation exposure to waterproofing spray can lead, in certain circumstances, to various respiratory disorders. Numerous cases of respiratory failures following the use of waterproofing sprays in confined home areas were reported in Germany between 1979 and $1983^{(1,3)}$, and in the United States, Canada and Japan in 1992-1993 ${ }^{(4,5,6)}$. These outbreaks of respiratory illness occurred following a formulation change in solvent (to eliminate ozone-depleting solvents) and fluorinated polymer (to increase solubility in the new solvent). The toxic mechanisms are not yet well understood but clinical findings and experimental data suggest that the new formulation may have played a central role in it because of: (1) the direct pulmonary cytotoxicity of the new fluorinated resins and, (2) a possible increase in the amount of respirable fluororesin particles emitted ${ }^{(7,8)}$. The latter is related to the change in the particle size distribution induced by the change of formulation.

In Switzerland, from January to March 2003, about 100 cases of respiratory symptoms due to the inhalation of waterproofing sprays were recorded, whereas less than 10 cases per year had been observed in the previous years. Most of the reported incidents are related to the domestic application of leather and textiles waterproofing sprays, which are of common use in housing activities. It must be stressed however that the same chemicals may be found in occupational activities and/or with less common waterproofing agents.

Three uncommon cases drew the attention of industrial hygienists and occupational physicians in Switzerland as they occurred after the professional use of a stain-repelling agent. In each case, the patients developed acute respiratory troubles within hours following the waterproofing of a tiled surface with a coating mixture containing a fluorinated polymer (a copolymer of fluorinated acrylate). 
The three workers' exposures occurred during two tile treatment activities within a two-month period ${ }^{(9)}$. In the first case, only the worker performing the waterproofing was involved, while in the second case, a painter, who was working in the same room, was also intoxicated. Both incidents occurred in the same company and involved the same product. The manufacturer of the waterproofing mixture indicated that its composition had been changed a few months ago although its commercial name remained the same. The new resin has been progressively introduced on the market as companies and suppliers renew their stock. It must be pointed out that the solvent substitution came also with a change in the fluorinated resin composition.

As the same waterproofing activity has been performed in the tile-company for years without any previous problem, it is strongly suspected that the composition change is somehow involved in the recent incidents. Considering that the health effects observed were located at an alveolar level and the solvents used in the coating mixture are common products of known toxicity, only two hypotheses remain plausible. (1) A change in the physical and chemical properties of the product generates a significant increase of exposure to respirable aerosols (2) The new resin generates unexpected toxic effects at an alveolar level, either by itself or combined with another factor (i.e. smoking, solvent).

A study was undertaken in order to modell the exposure conditions encountered during tile-waterproofing activities. Its goals were to determine the causes of the occupational incidents that had been reported and to characterize the exposure levels at which they had occurred. As the working conditions during the incidents were not known precisely, the study relied on laboratory experiments and numeric simulations. Aerosol emission rates were measured in controlled experimental conditions while the pollutant dispersion was calculated using exposure models. Similar measurements and calculations were conducted for solvent vapours in order to give a complete insight of exposure conditions. However, solvent vapours were not expected to play a central role in this specific case.

An examination of the polymer structure would be necessary for an in-depth study of its specific toxicity. At the present time, the detailed composition and nature of the new resin can unfortunately not be released publicly. This limitation prevents direct characterisation of the polymer. The emphasis has therefore been 
given to the assessment of solvent and aerosol exposures. While addressing hypothesis (1), the comparative evolution of exposure conditions with the old and new resin may indeed give indirect evidence in regards of hypothesis (2).

\section{CASES OF EXPOSURE}

The first case occurred after the waterproofing of a $15 \mathrm{~m}^{2}$ tiled-floor room (windows open). One hour after exposure, the worker developed a rapidly progressive dyspnea. On admission, he had severe hypoxemia. A similar case, involving the same waterproofing mixture, was reported about one month later. This time, the worker endured pulmonary collapse after treating a tiled wall in a bathroom, which was not ventilated. Another worker, who was painting in the same area, suffered respiratory discomfort and cough. A short investigation was undertaken in order to highlight the circumstances under which these incidents had taken place.

The manager of the tile-laying company and one of the workers involved were interviewed. It appeared that the waterproofing mixture was a ready-to-use commercial product (Patina-Fala) intended to coat tiles made of natural porous stone. In order to save time and to reduce the amount of material used, the coating is performed using a trigger spray as opposed to a paintbrush. The spraying of this type of coating resin has been carried out for 3 to 4 years and, until the recent health cases, no problem had ever been encountered before. However, as tiles made of natural stone are seldom used, this coating activity is only performed occasionally.

The three workers involved were healthy adults who had not suffered respiratory diseases or hypersensitivity to airborne pollutants prior to the incidents. The three of them were current or pastsmokers. The interviews conducted failed to clarify unambiguously whether or not some of them were smoking during the task. More information about the clinical aspects of the cases may be found in the related paper ${ }^{(9)}$ 


\section{METHODS}

\section{Emission source and product}

The waterproofing is achieved by applying a liquid resin containing a fluorinated polymer and a solvent on the material surface (tiles in our case). The solvent evaporation ensures the formation of a waterproof polymer layer. The resin is designed to be spread over the material surface with a paintbrush. However, in order to save time and to reduce the amount of resin used, the coating material is sometimes applied with a trigger spray. In this case, small particles as well as the large dispersion cone produced ensure the quick and regular application of a thin resin layer.

A manual trigger spray (3AN Canyon Corporation) was used in the tile company where the exposure cases occurred. The characteristics given by the manufacturer are as follows: Nozzle orifice: $\varnothing 0.4 \mathrm{~mm}$, spray output stroke. 1.1 gram \pm 0.2 gram (distilled water), spray pattern $\varnothing: 170 \mathrm{~mm} \pm 30 \mathrm{~mm}$ (at a distance of $150 \mathrm{~mm}$ ), spray angle $0^{\circ}-60^{\circ}$. The same system was used during the laboratory tests.

The composition of the polymer resin was changed recently. The old resin was a solution of fluorocarbonated polymer (polymer 1) into 1-methoxy-2-propanol (CAS 107-98-2, >50\% mass). Both solvent and polymer were changed in the new resin. The solvent was replaced by a mixture of isoparrafinic hydrocarbons $\left(\mathrm{C}_{9}-\mathrm{C}_{12}\right)$ (CAS 90622-57-4, 60-90\% mass) and glycol polymers of lower volatility, while another fluorocarbonated polymer was used. Unlike the former one, the new polymer is an fluoro-acrylate polymer. The product is fully polymerised prior to its application and the amount of remaining monomer within the mixture is very low (ppm) and therefore not expected to play a significant role in exposure. 


\section{Overspray emission and Transfer efficiency}

The transfer efficiency of the spray gun must be known in order to assess the aerosol emission during waterproofing. An estimate based on a theoretical approach is quite complex in the case of volatile aerosol emissions because key parameters, such as the diameter of droplets and their velocity, become time dependent. This time variability keeps the properties of droplets from being measured directly without significant bias.

The transfer efficiency has been assessed experimentally, using a mass balance similar to the one proposed by Tan and al. ${ }^{(10)}$. It must be pointed out that theoretical models have been developed by previous authors to predict the transfer efficiency from compressed air spray guns during painting ${ }^{(11)}$. But, as in our case the spray emission is not generated by a compressed gun but by a manual trigger spray, their use seems limited.

\section{Experimental}

As shown in Figure 1, the spraying was performed into a ventilated hood, in which a simple cardboard box was set. The upper and lower faces of the box were open, which created an ascending airstream of $0.8 \mathrm{~m} / \mathrm{s}$. A hole was also set into the central part of the front face in order to spray inside the box. The inner face of the box in front of the hole was covered by an aluminium-coated surface. During the spraying, the large particles impacted on the aluminium-coated surface while the smaller particles, constituting the overspray mist, escaped with the airstream line. As the impacted resin mixture tends to drip, a collecting plate was set below the box. At the end of each experiment, the spray gun, the aluminium-coated surface and collecting plate were weighted. In addition, the particles concentration in the overspray was measured using a lightdispersion based device, a Grimm Dust Monitor (model 1.102, Labortechnik mbH, calibrated with stearine by the manufacturer). This measure allowed estimations of overspray emission rates. 
(Figure 1 about here)

Spraying experiments were conducted during 4-5 minutes with resin mixtures 1 and 2. The experimental conditions of emission were as follows: spray angle was $60^{\circ}$. The distance between the spray nozzle and the collecting surface was 30 centimetres. The ascending air streamline into the box was $0.8 \mathrm{~m} / \mathrm{s}$.

\section{Assessing solvent emissions}

The main part of the two resins mixture is constituted of volatile solvents (1-methoxy-2-propanol and branched hydrocarbons). Thus, a significant concentration of solvent is expected in the workers' breathingzone during spraying. Considering the possible conditions of the evaporation process, three sources of solvent vapours can be distinguished: (1) emission coming from the impacted material (impacted surface), (2) emission coming from the overspray, and (3) emission coming from the impacted particles during their transport.

\section{Solvent emissions from the impacted material.}

Laboratory measurements were conducted in order to assess the solvent emission due to the impacted surface. These measurements were taken place in a stainless steel $13 \mathrm{~m}^{3}$-experimental room of controlled ventilation conditions. The air renewal in the experimental room is ensured by an independent ventilation system, of adjustable recycling ratio.

The resin mixture to be measured is coated on a $1 \mathrm{~m}^{2}$ metallic plate placed on a table at the room centre. The solvent concentration is measured in the downstream air with a direct reading photoionisation Toxirae detector (RAE systems inc., $10.6 \mathrm{eV}$, calibrated against an infrared photoionisation detector MIRAN before the experiment). The emission rate may be deduced on the basis of the measured concentrations. As experimental or field conditions differ significantly from the ideal well-mixed room case, a general 
dispersion model including air recycling was used. The equation [1] considers theoretical concentrations and time coefficients $\left(\mathrm{C}_{1}, \mathrm{C}_{2}, \mathrm{k}_{1}, \mathrm{k}_{2}\right)$.

$C(t)=C_{1} \cdot \exp \left(-k_{1} \cdot t\right)+C_{2} \cdot \exp \left(-k_{2} \cdot t\right)$

Introducing the emission factor $\mathrm{E}$, leads to equation 2. In known ventilation conditions, the emission rate may be easily deduced from the concentration evolution.

$C(t)=\frac{E}{Q}-\frac{E}{2 Q}\left(\exp \left(-k_{1} \cdot t\right)+\exp \left(-k_{2} \cdot t\right)\right)$

Preliminary experiments using tracer gas $\left(\mathrm{SF}_{6}\right)$ and emission from surfaces of well-known solvents (isooctan and c-hexan) were carried out to characterize the dynamic behaviour of the chamber and fit the experimental parameters.

These experiments have also shown that two theoretical models may be used to predict the emission into the experimental room: the one proposed by Hummel (1996) and the one proposed by Gmehling (1989). A comprehensive description of these models may be found in previous publications ${ }^{(12,13)}$.

\section{Solvent emissions from droplets.}

The solvent emissions from droplets have been described by other authors and its detailed developments may be found in the literature ${ }^{(13,14,15)}$. The diffusion phenomenon, which is the limiting factor of the masstransfer process, is described by Fick's general law of diffusion. The emisson rate per unit area G depends on the diffusion coefficient $\mathrm{D}$ and on the mass or concentration gradient.

$G_{j}=-D_{j} \cdot \frac{\partial C_{j}}{\partial x}$ 
Fick's relationship may be applied to the evaporation process of liquid droplets in a straightforward way if we assume the following hypotheses: (1) the particles are of spherical symmetry, (2) a quasi-steady state in gas, (3) D and $\rho$ are independent of the particles radius (4), the distance between the particles is large, and (5) there are no chemical reactions. The mass transfer at a given time of the evaporation process is strongly dependent on the vapour pressure gradient between the droplet surface $\mathrm{P}_{\mathrm{di}}$ and the ambient air $\mathrm{P}_{\mathrm{ai}}$. It may be expressed as:

$J(t)_{j}=4 \cdot \Pi \cdot r(t) \cdot D_{j} \cdot M \cdot \frac{\left(P_{d i}-P_{a i}\right)}{R \cdot T}$

In this case study, the droplets are made of volatile solvents as well as non-volatile material (resins). It implies that the droplet will never completely evaporate and that its composition will change over time. Assuming a linear relationship between the particulate fraction of volatile material and its vapour pressure at the droplet surface, $\mathrm{P}_{\mathrm{di}}$ may be expressed as:

$P_{d i}=X_{i} \cdot P_{s i}$, where the mass fraction $\mathrm{X}_{\mathrm{i}}$ at a given time is:

$X_{i}=\frac{m_{i}}{m_{t o t}}$

The relationships given in equations 4,5 and 6 have been used to implement a numerical simulation of the droplet evaporation. The numeric model has been implemented on Ithink (version 5.0, HPS High Performance Systems, Inc., Hanover, NH), a flow-processing program.

A theoretical simulation of the droplets evaporation has been conducted using the relationships given in equations 3 to 6 . The numeric values used are presented in Table I. The parameters related to the resin properties have been extracted from technical sources, such as the Material Safety Data Sheets, given by 
different suppliers of similar waterproofing mixtures. Only the evaporation of the $\mathrm{C}_{9}-\mathrm{C}_{12}$ hydrocarbons fraction, which constitutes the main volatile compound of resin 2 , has been considered during the simulation.

(Table I about here )

\section{Assessing dispersion and breathing-zone concentrations.}

The exposure conditions (such as ventilation condition) at the time of the incidents are not known with certainty. For this reason, and because of practical difficulties (i.e. the difficulty to perform personal measurement with the direct reading instrument), the exposure levels have been assessed through modelling. This method enables to carry out an analysis of sensitivity with regard to the simulation parameter.

As this study focuses on alveolar-level effects, our concern regarding particulate matter is limited to respirable aerosols $(<10 \mu \mathrm{m})$. Because of their limited mass and size, it can be assumed that fine particles are not affected significantly by the gravitation and aerodynamic forces shortly after their emission and thus, behave in a similar way to gases with regard to their transportation and dispersion. The well known two-compartment model has therefore been used to assess both solvent and overspray concentrations in the workers' breathing zone ${ }^{(16)}$.

Two ideally mixed dispersion zones are considered: the far-field (FF) and the near-field (NF) volume. The first one being the room volume and the second one the "virtual" volume, representing the breathing zone near the emission source. Near and Far-field zones are interconnected by an inter-compartment flow $\mathrm{Q}_{\mathrm{e}}$, which ensures the air and pollutant circulation. The evolution of the pollutant concentration into the two compartments is given in equations 7 and 8 .

$V_{N F} \cdot d C_{N F}=\left(E+Q_{e} \cdot C_{F F}-Q_{e} \cdot C_{N F}\right) \cdot d t$ 
$V_{F F} \cdot d C_{F F}=\left(Q_{e} \cdot C_{N F}-\left[Q+Q_{e}\right] \cdot C_{F F}\right) \cdot d t$

\section{(Figure 2 about here )}

Similarly to the droplet evaporation calculation, the dispersion has been assessed through numerical simulations using Ithink (version 5.0).

The overspray emission and the surface emission rates assessed by experimentation have been introduced in a two-zone model. The ventilation and room parameters used in the calculation were estimated on the basis of the incidents description given by the workers and the company manager. The default parameters as well as the range values used to perform a sensitivity analysis with the key parameters of the models are presented in Table II.

The exposure conditions in room 1 are representative of "good" working conditions, as the room surface is large and the estimated renewal rate is high. Comparatively, the conditions in room 2 may be regarded as "poor" because of its reduced volume and fresh air supply. It must be pointed out that the ventilation conditions in room 2 are not known with certainty. The renewal rate has been fixed at a low value as it is suspected that there were no windows or source of fresh air. Moreover, this choice allows a comparison of potential exposures in a wide range of working conditions.

(Table II about here ) 


\section{RESULTS AND DISCUSSION}

\section{Overspray emission}

Concentrations in particles between 0.5 to $10 \mu \mathrm{m}$ were found to be about $44 \mathrm{mg} / \mathrm{m}^{3}$ for resin mixture 1 and about $13 \mathrm{mg} / \mathrm{m}^{3}$ for resin mixture 2. Assuming a homogenous concentration of overspray in the air streamline at the level of the measuring device, the overspray emission rate may be calculated using the airstream volumic flow and the measured concentrations. The emission rate of particles smaller than $10 \mu \mathrm{m}$ is $0.66 \mathbf{~ m g} / \mathbf{s}(\mathrm{SD} 0.10$ ) for resin 1 and $\mathbf{0 . 3 7} \mathbf{~ m g} / \mathbf{s}$ (SD 0.04) for resin 2. Despite the variable nature of manual spraying, the size distributions in the overspray are surprisingly regular for the two resins (Figure 3). The main part of the overspray generated with resin 1 is made of large particles $(>10 \mu \mathrm{m})$ while the one generated with resin 2 shows a maximum in the range of 2-5 $\mu \mathrm{m}$.

The differences observed between the two distributions show that a greater proportion of particles issued from resin 2 may reach the alveoli. Considering the range of size-fractions measured and the likelihood to reach the alveoli for a given particle size (standardized distribution curves ${ }^{13}$ ), it appears that the respirable proportion in the overspray is $\mathbf{2 8 - 6 7} \%$ for resin 1 and $\mathbf{3 7 - 7 5} \%$ for resin 2 .

(Figure 3 about here )

A comparative weighting between the mass of impacted droplets (on the aluminium-coated surface and the collecting plate) and the total mass of waterproofing mixture used indicates that the transfer efficiency is of about $\mathbf{6 0 \%}$ for resin 1 and $\mathbf{8 0 \%}$ for resin 2 . This result indicates that 20 to $40 \%$ of the remaining nonimpacted material has gone with the air streamline as overspray or has been evaporated (either during transport or after impaction). Despite the short experimentation time (about 5 minutes for each spraying experiment), a significant amount of solvent may evaporate during measurement, either from the coated surface or from the droplets during their air transport. The transfer efficiency obtained is therefore quite 
conservative and should be considered as a lower bond value. The difference observed between the transfer efficiency of the two resins may be easily explained by the fact that the new waterproofing mixture (resin 2) generates less overspray and is less volatile than the old one.

The ratio between the measured overspray concentration and the calculated mass balance loss is about $1 \%$. This surprisingly low result suggests either: (1) a high degree of evaporation (2) the presence, in the overspray, of large particles falling out of the range of the measuring device or settling out prematurely. Although the evaporation is not negligible, this last effect seems predominant as similar ratios have been obtained while spraying 1,2-propanediol, a non-volatile liquid (results not shown). The bias in the assessment of the overspray emission due to the presence of these large particles does not affect our study, which is focused on respirable particles.

\section{Solvent emission from impacted material}

The emission rates obtained experimentally from coated surfaces are presented in Figure 4. Despite the large measurement time (about $6 \mathrm{hrs),} \mathrm{the} \mathrm{emission} \mathrm{rate} \mathrm{does} \mathrm{not} \mathrm{show} \mathrm{a} \mathrm{dramatic} \mathrm{decrease} \mathrm{over} \mathrm{time.} \mathrm{This}$ is particularly true for resin 1 , for which the emission is almost constant. The mean emission rate for resin 1 is $\mathbf{1 9 . 8}\left[\mathbf{m g} / \mathbf{s} \cdot \mathbf{m}^{2}\right]$ (SD 3.7). Resin 2 is characterized by a first period of regular emission rate (from $0 \mathrm{~s}$ to $4 \cdot 10^{3} \mathrm{~s}$ ), followed by a decreasing slope (from $4 \cdot 10^{3} \mathrm{~s}$ to $9 \cdot 10^{3} \mathrm{~s}$ ) and a new regular period (after $9 \cdot 10^{3} \mathrm{~s}$ ).

This emission profile is due to the composite nature of the solvent used in resin 2 . In the first period, the volatile fraction of the $\mathrm{C}_{9}-\mathrm{C}_{12}$ hydrocarbons strongly influences the emission rate. Once the volatile compounds evaporate, the emission rate depends only on the remaining, less volatile, part of the solvent. This over-vaporisation explains why the initial emission rate is similar to resin 1 despite the lower mean vapour pressure expected for resin 2 . The waterproofing activity is usually short. Thus, the emission rate to be considered, in the case of coated surfaces, should be the initial one. The mean emission value for the first period of the profile is $\mathbf{1 8 . 8}\left[\mathbf{m g} / \mathbf{s} \cdot \mathbf{m}^{2}\right]$ (SD 3.4). 
(Figure 4 about here $=$

\section{Solvent emission from droplets}

As shown in Figure 5 (a) the application of an isothermal diffusion model to "ideal" spherical particles leads to a very quick evaporation process. The particles in the range of $10 \mu \mathrm{m}$ reach their minimal radius within $2 \cdot 10^{-1}$ seconds; after this period of time, almost all the volatile fraction is evaporated and the particles are essentially composed of non-volatile material. Significant differences may be observed between resin 1 and resin 2, mainly because of the difference of vapour pressure between the two volatile solvents. Despite this, it should be observed that the evaporation time for both resins falls within the same order of magnitude.

Fick's diffusion equation is adequate to depict molecular diffusion driven by the concentration gradient. In our case (turbulent conditions) the equivalent diffusivity coefficient is usually $10^{2}$ to $10^{4}$ higher. Thus, the evaporation rate of the droplets at the spray nozzle or between the spray nozzle and the impaction (for large particles) is significantly higher.

Except for the initial particle diameter, the model shows little sensitivity to the variation of the simulation parameters. The initial-diameter sensitivity may be easily explained by the wide range of possible particle sizes and the fact that it strongly affects the particle volume and mass $\left(\sim \mathrm{d}^{3}\right)$. The effect of the initial particle size on the evaporation kinetics is presented in Figure 5 (b). The evaporation of respirable particles falls within $1 \cdot 10^{-2}$ to $2 \cdot 10^{-1} \mathrm{~s}$.

(Figure 5 about here ) 
The evaporation times obtained are surprisingly short. However, when considering the basic hypothesis used in the model, they should be interpreted carefully. It has for instance been assumed that the particles were homogenous and that gas diffusion was the limiting process of their evaporation. These assumptions are certainly not valid when the resin polymer becomes the main particle constituent. In this latter case, the evaporation may be limited by the migration of the liquid solvent inside the droplets. Because of this phenomenon, residue of solvents may be expected to remain inside the particles much longer than calculated.

Despite the model limitations and with regard to the order of magnitude of the evaporation times obtained, it can be assumed that the main part of the volatile solvent in the overspray evaporates in the near-field of the worker during spraying.

\section{Overspray and solvent dispersion}

\section{Overspray dispersion}

As shown in Figure 6 (a), there are significant differences in the concentrations calculated for resin 1 and resin 2. Both near-field and far-field concentrations are about two times higher for resin 1 . This difference is due to the higher emission rate of particles $<10 \mu \mathrm{m}$ of resin 1 . As the main part of this overspray is made of particles between 2 and $5 \mu \mathrm{m}$, the amount of respirable particles generated by resin 1 is less than two times higher than the one produced by resin 2 . The results also show large decreases between near-field (NF) and far-field concentrations (FF), the latter being two to three times lower (see Figure 6 a,b,c).

In room 1, the situation tends to become stationary after about 10 minutes, while the concentration in room 2 is still increasing after 40 minutes (Figure 6 b). In practice however, the situation never becomes stationary because of the intermittent nature of the tile-coating work (other tasks, changing working location...). This is particularly true during the use of a manual trigger spray, which must be refilled regularly. The two-zone model has been implemented to take this factor into account assuming a 10-minute 
cycle emission (10 minutes spraying, 10 minutes refilling and/or performing other activities). The nearfield concentrations that are calculated are presented in Figure 6 (c). The mean values obtained for room 1 and 2 are respectively 12 and $60\left[\mathrm{mg} / \mathrm{m}^{3}\right]$ for resin 1 and 7 and $34\left[\mathrm{mg} / \mathrm{m}^{3}\right]$ for resin 2.

Sensitivity analyses have been conducted to assess the impact of the variability of various parameters (E, Q, $\mathrm{Q}_{\mathrm{e}}$ ). Variations of $\mathrm{Q}$ and $\mathrm{E}$ within the upper and lower bound values considered (see table III) do not have a major impact on the calculated concentrations. The sensitivity to a change of the inter-compartment flow Qe is however high, as a fivefold increase in Qe leads to a decrease of about 4 in the exposure concentrations (see Figure 6 d).

(Figure 6 about here )

\section{Solvent dispersion from impacted surface emissions}

A comparison of the calculated concentrations in room 2 (corresponding to "poor" exposure conditions) for the two resins is presented in Figure 7 (a). The near-field concentrations become stationary, after a 15minute period of time, at $\mathbf{7 0 0} \mathbf{~ p p m}$ for solvent vapours of resin 1 and $\mathbf{3 5 0} \mathbf{~ p p m}$ for solvent vapours of resin 2, while the far-field concentrations are about 7 times lower.

As shown in Figure 7 (b), the room size and general ventilation conditions dramatically affect the near-field concentrations. The solvent concentrations from resin 2 are reduced by a factor six when emitted into room 1 rather than room 2, room 1 being representative of "good" working conditions. In the far-field range, the decrease due to the improvement of working conditions is less perceptible and the calculated concentrations are in the same order of magnitude. One should also note that the near-field concentration in room 2 is only about 1.7 times higher than the far-field concentration in room 2.

The near-field level of pollutants exhibits a significant sensitivity to inter-compartment ventilation Qe and to the emission rate $\mathrm{G}$. The results obtained for room 2 indicate that a variation of Qe and $\mathrm{G}$, within the range given in table III, produce concentrations varying, respectively, in a range of 4 and 2. 
The size of the evaporating surface has a severe impact on the near-field concentrations (see Figure $7 \mathrm{c}$ ). This parameter is a major concern in the process of exposure assessment because of the large scale of possible values. In the two-zone model, the emitting surface is limited because it must be located within the near-field volume. Nevertheless, the experimentation has shown that the coated surface emits solvent vapours during several hours. Thus, in the case of occupational waterproofing of large surfaces, noticeable solvent quantities may also be emitted in the far-field range. This situation, which corresponds to the exposure cases reported, has been considered during simulation. The results obtained for a combination of $1 \mathrm{~m}^{2} \mathrm{NF}$ and $6 \mathrm{~m}^{2} \mathrm{FF}$ emitting surfaces are presented in Figure 7 (d). It is shown that the FF emission dramatically increases the ambient concentration and significantly affects the worker's breathing zone.

In a general sense, it can be assumed that the concentrations calculated are pessimistic because of the conservative nature of the model. The real emission rates on porous material are for instance very likely lower than the ones measured on a non-absorbing surface. The concentrations calculated should then be used carefully and considered as orders of magnitude rather than absolute values. Although limited in an absolute sense, the model that is used is of utmost interest when comparing simulation results in a relative way.

(Figure 7 about here )

\section{Study limitations}

The assessment strategy chosen to characterize exposure suffers two significant limitations.

The aerosol measurement method that is used (light-dispersion device) is unspecific. Its results are expressed in terms of total resin mass for a given size fraction of particles. Assuming that some solvent remains in the resin particles, this value is higher than the effective amount of polymer reaching the alveoli. Although simulations indicate that the evaporation process is extremely short for fine particles, this effect may be significant for resin 2, which contains solvents of low-volatility. Moreover, as the toxicological 
mechanism is not known, it is unclear how the polymer mass metric is related to the health effects observed.

The exposure models are known to give rough estimates of real exposure conditions. The concentrations obtained should therefore be considered carefully. In our case, because of the conservative assumptions used during the model implementation, the results are likely to be pessimistic. Besides, this drawback is not relevant when these models are used in a relative sense to compare different exposure conditions. 


\section{CONCLUSIONS}

The results of the investigations undertaken are summarized in table IV. None of the results obtained indicate that the change of resin composition has increased the levels of solvents or aerosol in the workers' breathing zone. It must be pointed out that these findings differ from the results obtained with other fluorinated polymers, as reported by previous authors ${ }^{(7,8)}$. On the contrary, data suggests that the exposure levels to both resin overspray and solvents have been significantly reduced. (1) The emission rate and breathing zone concentrations in particles $<10 \mu \mathrm{m}$ are about two times lower with the new resin. This decrease is partly mitigated due to the different particle-size distribution of the two resins. Nevertheless, the respirable fraction ranges estimated suggest that a smaller amount of particles reach the alveoli when using the resin 2. (2) In similar work conditions, resin 2 tends to generate solvent concentrations two times lower. Moreover, the solvent fraction used in resin 2 may be regarded as of lower toxicity. No exposure limits are given ${ }^{(17)}$ for the isoparraffinic hydrocarbon mixture used as solvent in resin 2, but toxicological data suggests a low toxicity. The alcanes isomers, such as the iso-alcanes, have for instance a threshold limit of $200 \mathrm{ppm}$ (TWA), which is two times lower than the one of the 1-methoxy-2-propanol (TWA $100 \mathrm{ppm}$, STEL $150 \mathrm{ppm})$.

These results strongly suggest that cases of acute respiratory illness are related to the resin polymer rather than an increase in exposure levels. This toxicity may be due to the polymer by itself or by interaction between the polymer and other factors (such as solvent and/or smoking). This hypothesis is also enhanced by the simulation results of the droplets evaporation, which indicate that the particles reaching the alveoli are essentially made of non-volatile material. One should point out that the results obtained support the theory of a specific toxicity of some fluorinated resins reported by previous authors.

(Table IV about here ) 
When injected in a two-zone model, the solvent emissions measured lead to exposure levels of several hundred ppm with both resins. Thus, not surprisingly, it appears that in "poor" ventilation conditions, the tile coating activity is potentially harmful in terms of solvent exposure.

The concentration level at which acute effects may occur with the new resin appears to be quite low and may therefore occur in numerous exposure conditions. The overspray concentration assessed for the acute exposure case in "good" working conditions is about $7 \mathrm{mg} / \mathrm{m}^{3}$. Considering that the polymer is the probable cause of the problem, these results raise serious concerns regarding both occupational and domestic exposures. Fluorinated polymer is indeed a generic product, which may be used in several coating sprays or mixtures in various countries.

It is interesting to note that, following the recent outburst of exposure cases, several domestic sprays have been withdrawn from the Swiss market (Rapi Aqua stop, Rapi Intemp, K2r). The Public Health Office, which is in charge of this case, indicated that an interaction between the polymer and the heptane solvent was suspected. These products appeared to use the same polymer resin as the stain-repelling agent considered in this study (Patina-Fala). Following the three exposure cases, a warning was issued to reinforce the safety measures in the use of this product.

\section{RECOMMENDATIONS}

The stain-repelling agent considered in this study is inadequate for spraying. Its coating should only be performed through non-nebulizing process (i.e paintbrush application) and, as skin contact is likely, with adequate dermal protection. When injected in a two-zone model, the solvent emissions that were measured lead to exposure levels of several hundred ppm with both resins. Thus, not surprisingly, it appears that in "poor" ventilation conditions, the tile coating activity is potentially harmful in terms of solvent exposure. Although quite pessimistic because of the conservative assumptions of the model, these results indicate that, notwithstanding the aerosol exposure issue, preventive measures should be applied during 
waterproofing with both resins. In any case, an adequate room ventilation and personal protective equipment are therefore required.

It must also be pointed out that the use of a trigger spray as opposed to a paintbrush contributes to increase the exposure to the solvent. As a matter of fact, the particles generated by the spray evaporate rapidly (within $1 \cdot 10^{-2}$ to $2 \cdot 10^{-1} \mathrm{~s}$ for respirable particles). The limited spray transfer efficiency that was measured ( $80 \%$ for resin 2$)$ as well as the mass balance "losses" observed suggest a significant solvent emission rate from particles during spraying. The use of a trigger spray without adequate protective measure is therefore not recommended.

Emission and dispersion modelling have shown here to be interesting approaches to retrospectively assess exposure conditions. Information obtained could now be extrapolated to other working conditions (environment and work processes). Further work should be undertaken to (1) improve development and validation of such modelling tools, and (2) investigate the relationship between fluoro-polymer exposure assessment and toxic effects (mechanism, health effects).

\title{
LIST OF SYMBOLS
}

\author{
C Mass concentration $\left[\mathrm{g} / \mathrm{m}^{3}\right]\left[\mathrm{mg} / \mathrm{m}^{3}\right]$ or $\left[\mu \mathrm{g} / \mathrm{m}^{3}\right]$ \\ $\mathrm{C}_{0}$ incoming conc., $\mathrm{C}_{\mathrm{FF}}$ far-field conc., $\mathrm{C}_{\mathrm{NF}}$ near-field conc. \\ $\mathrm{C}_{1}, \mathrm{C}_{2}$ Concentration coefficients $\left[\mathrm{g} / \mathrm{m}^{3}\right]\left[\mathrm{mg} / \mathrm{m}^{3}\right]$ or $\left[\mu \mathrm{g} / \mathrm{m}^{3}\right]$ \\ D Diffusion coefficient $\left[\mathrm{m}^{2} / \mathrm{s}\right]$ \\ E Emission rate $[\mathrm{g} / \mathrm{s}][\mathrm{mg} / \mathrm{s}]$ or $[\mu \mathrm{g} / \mathrm{s}]$ \\ G Surface emission rate $\left[\mathrm{kg} / \mathrm{m}^{2} \cdot \mathrm{s}\right]$ \\ J Mass flux $[\mathrm{kg} / \mathrm{s}]$ \\ $\mathrm{k}_{1}, \mathrm{k}_{2} \quad$ Time coefficients $\left[\mathrm{s}^{-1}\right]$ \\ m Mass $[\mathrm{kg}]$ or $[\mathrm{g}]$
}




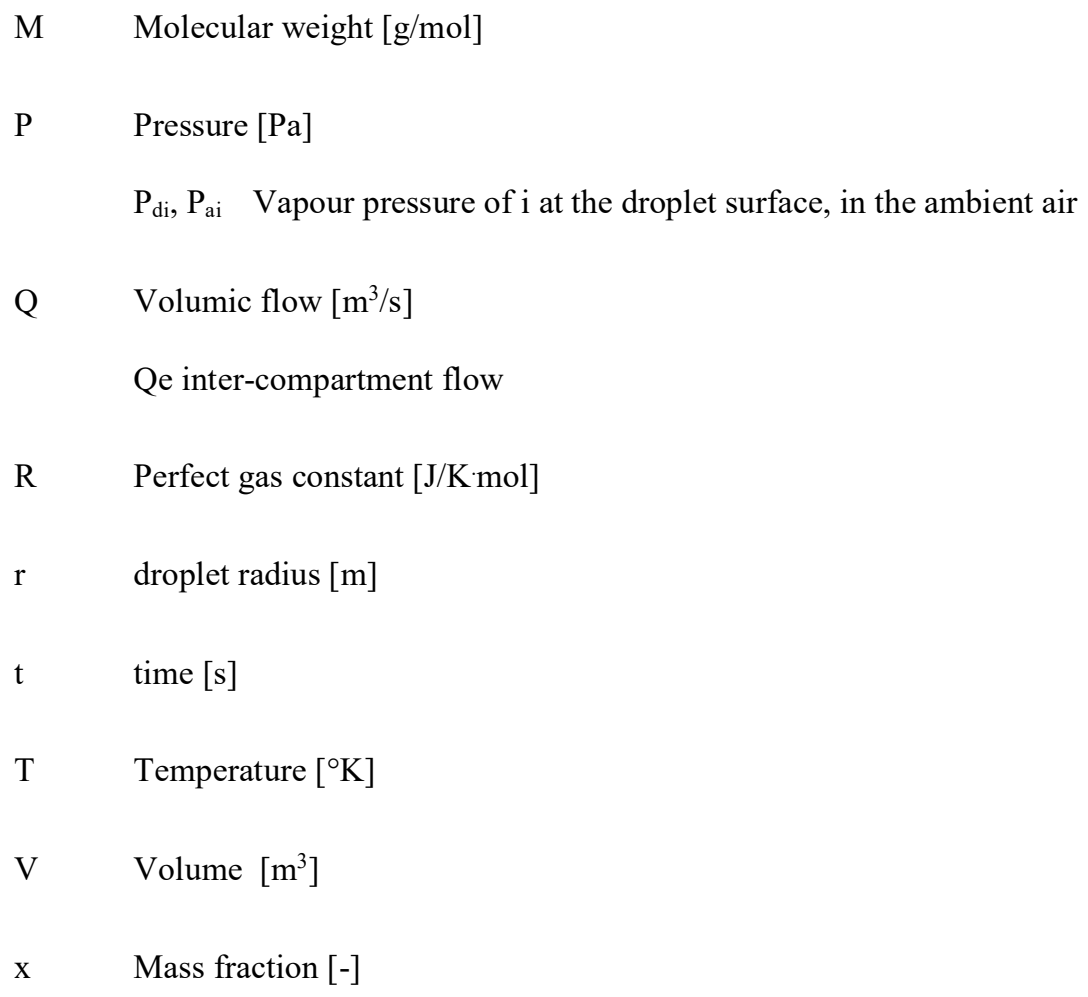

\section{REFERENCES}

1. Grainger, D.; Stewart, C.: Fluorinated coating and Films: Motivation and significance. In: Fluorinated Surfaces, Coatings and Films, D.G. Caster and D.W. Grainger, eds., pp. 1-14. (ACS symposium series; 787). American Chemical Society, Washington (2001).

2. Muller-Esch, G.; Brunk, E. ; Djonlagic, H. ; et al.: Pulmonary Effect of Inhaling Leather Impregnation Sprays. Dtsch Med Wochenschr 107(18): 692-695 (1982).

3. Okonek, S.; Reinecke, H.J.; Fabricius, W.; et al.: Poisoning with Leather-Impregnation Sprays. A Retrospective Analysis of 224 Cases of Poisoning. Dtsch Med Wochenschr 108(49): 1863-1867 (1983). 
4. Tanino, M.; Kamishima, K.; Miyamoto, K.; et al.: Acute Respiratory Failure Caused by Inhalation of Waterproofing Spray Fumes. Nihon Kokyuki Gakkai Zasshi 37(12): 983-986 (1999).

5. Smilkstein, M.J.; Burton, B.T.; Keene, W.; et al.: Acute Respiratory Illness Linked to Use of Aerosol Leather Conditioner. Morb Mortal Wkly Rep 41(52-53): 965-967 (1993).

6. Burkhart, K.K.; Britt, A.; Petrini, G.; et al.: Pulmonary Toxicity Following Exposure to an Aerosolized Leather Protector. J Toxicol Clin Toxicol 34(1): 21-24 (1996).

7. Yamashita, M.; Tanaka, J.: Pulmonary Collapse and Pneumonia due to Inhalation of a Waterproofing Aerosol in Female CD-1 mice. J Toxicol Clin Toxicol 33(16): 631-637 (1995).

8. Hubbs, A.F.; Castranova, V.; Ma, J.Y.C.; et al.: Acute Lung Injury Induced by a Commercial Leather Conditioner. Toxicol Appl Pharmacol 143: 37-46 (1997).

9. Lazor-Blanchet, C.; Rusca, S.; Vernez, D.; et al. : Acute Pulmonary Toxicity Following Occupational Exposure to a Floor Stain-protector. Submitted for publication in: Int Arch Occup Environ Health.

10. Tan, Y.M.; Flynn, M.R.: Methods for Estimating the Transfer Efficiency of a Compressed air Spray Gun. Appl Occup Environ Hyg 17(1): 39-46 (2002).

11. Flynn, M.R.; Gatano, B.L.; McKernan, J.L.; et al.: Modelling Breathing-zone Concentrations of Airborne Contaminants Generated During Compressed Air Spray Painting. Ann Occup Hyg 43(1): 67-76 (1999).

12. Wadden, R.A.; Scheff, P.A.: Air Quality Models. In: Indoor Air Pollution, Characterization, Prediction, and Control, pp. 105-132. Ed. J. Wiley, Inc. New York (1983).

13. Vincent, J. H.: Aerosol Science for Industrial Hygienists. Pergamon Press, New York (1995).

14. Hinds, W. C.: Evaporation (chapter 13.7), in Aerosol Technology. Properties, Behavior and Measurement of Airborne Particles. Wiley-Interscience, New York (1982).

15. Sirignano, W. A.: Theory of isolated droplet vaporization, heating and acceleration (chapter 2), in Fluid Dynamics of Droplets and Sprays. $1^{\text {st }}$ ed. Cambridge University Press, Cambridge (1999).

16. Keil, C.B. Ed.: Mathematical Models for Estimating Occupational Exposure to Chemicals. American Industrial Hygiene Association (AIHA), Fairfax (2000). 
17. National Institute of Occupational Safety and Health (NIOSH). Registry of Toxic Effects of Chemical Substances. CD-ROM. Canadian's National Centre for Occupational Health and Safety (CCOHS),

Hamilton (2003). 


\section{TABLES AND FIGURES}

\begin{tabular}{lcc}
\cline { 2 - 3 } & resin 1 & resin 2 \\
\hline Molecular weight, $\mathrm{M}$ & $90.1[\mathrm{~g} / \mathrm{mol}]$ & $158[\mathrm{~g} / \mathrm{mol}]$ \\
Solvent mass fraction, $\mathrm{X}_{\mathrm{i}}$ & $0.8[-]$ & $0.8[-]$ \\
Fick's Diffusion coefficient, D & $8 \cdot 10^{-6}\left[\mathrm{~m}^{2} / \mathrm{s}\right]$ & $6 \cdot 10^{-6}\left[\mathrm{~m}^{2} / \mathrm{s}\right]$ \\
Vapour pressure, $\mathrm{P}_{\mathrm{s}}$ & $1.4[\mathrm{kPa}]$ & $0.2[\mathrm{kPa}]$ \\
Particle radius, $\mathrm{r}$ & $5[\mu \mathrm{m}]$ & $5[\mu \mathrm{m}]$ \\
Near-field concentration, $\mathrm{C}_{\mathrm{NF}}$ & $0\left[\mathrm{mg} / \mathrm{m}^{3}\right]$ & $0\left[\mathrm{mg} / \mathrm{m}^{3}\right]$ \\
Temperature, $\mathrm{T}$ & $293\left[{ }^{\circ} \mathrm{K}\right]$ & $293\left[{ }^{\circ} \mathrm{K}\right]$ \\
Particle specific mass & $0.9\left[\mathrm{~g} / \mathrm{cm}^{3}\right]$ & $0.8\left[\mathrm{~g} / \mathrm{cm}^{3}\right]$ \\
\hline
\end{tabular}

${ }^{A}$ Values for the 1-methoxy-2-propanol

${ }^{\text {B }}$ Mean value for hydrocarbons (C9-C12), the main volatile compound of resin 2

Table I.

Implementation values for the simulation of droplets evaporation. 


\begin{tabular}{lccc}
\cline { 2 - 4 } & room 1 & room 2 & Range \\
\hline Compartment volume, $\mathrm{V}$ & $43\left[\mathrm{~m}^{3}\right]$ & $12\left[\mathrm{~m}^{3}\right]$ & - \\
Near-field volume, $\mathrm{V}_{\mathrm{NF}}$ & $2\left[\mathrm{~m}^{3}\right]$ & $2\left[\mathrm{~m}^{3}\right]$ & - \\
Ventilation flow, Q & $0.06\left[\mathrm{~m}^{3} / \mathrm{s}\right]$ & $0.04\left[\mathrm{~m}^{3} / \mathrm{s}\right]$ & 1 to 5 renewals per hr. \\
Inter-compartment flow, Qe & $0.04\left[\mathrm{~m}^{3} / \mathrm{s}\right]$ & $0.008\left[\mathrm{~m}^{3} / \mathrm{s}\right]$ & 0.0055 to $0.028\left[\mathrm{~m}^{3} / \mathrm{s}\right]$ \\
Overspray emission rate, & $0.66[\mathrm{mg} / \mathrm{s}]$ & $0.66[\mathrm{mg} / \mathrm{s}]$ & - \\
resin 1 & & & \\
Overspray emission rate, & $0.37[\mathrm{mg} / \mathrm{s}]$ & $0.37[\mathrm{mg} / \mathrm{s}]$ & $0.29-0.45[\mathrm{mg} / \mathrm{s}](+/-2 \mathrm{SD})$ \\
resin 2 & & & \\
Emission rate, resin 1 & $19.8\left[\mathrm{mg} / \mathrm{sm}^{2}\right]$ & $19.8\left[\mathrm{mg} / \mathrm{sm}^{2}\right]$ & $12.4-27.2\left[\mathrm{mg} / \mathrm{sm}^{2}\right](+/-2 \mathrm{SD})$ \\
Emission rate, resin 2 & $18.8\left[\mathrm{mg} / \mathrm{sm}^{2}\right]$ & $18.8\left[\mathrm{mg} / \mathrm{sm}^{2}\right]$ & $12.0-25.6\left[\mathrm{mg} / \mathrm{sm}^{2}\right](+/-2 \mathrm{SD})$ \\
Coated surface & $1\left[\mathrm{~m}^{2}\right]$ & $1\left[\mathrm{~m}^{2}\right]$ & $0.5-2\left[\mathrm{~m}^{2}\right]$ \\
\hline
\end{tabular}

Table II

Implementation values for the two-zone model. 


\begin{tabular}{lcc}
\cline { 3 - 3 } & resin 1 & resin 2 \\
\hline $\begin{array}{l}\text { Overspray inhalable concentration } \\
{\left[\mathrm{mg} / \mathrm{m}^{3}\right]}\end{array}$ & $12-60$ & $7-34$ \\
Overspray respirable fraction [\%] & $28-67$ & $37-75$ \\
Overspray composition & $\begin{array}{c}\text { Fluorinated resin 1 } \\
\text { (fluoro-hydrocarbon) }\end{array}$ & $\begin{array}{c}\text { Fluorinated resin 2 (fluoro-acrylate), } \\
\text { high molecular weight glycol } \\
\text { polymers }\end{array}$ \\
Solvent vapour concentration [ppm] & 700 & 350 \\
Solvent vapour composition & 1-methoxy-2-propanol & $\begin{array}{c}\text { Volatile fraction of the Isoparrafinic } \\
\text { hydrocarbons }\left(\mathrm{C}_{9}-\mathrm{C}_{12}\right)\end{array}$ \\
\hline
\end{tabular}

Table III

Summary of the assessed exposure concentration in the worker's breathing zone 


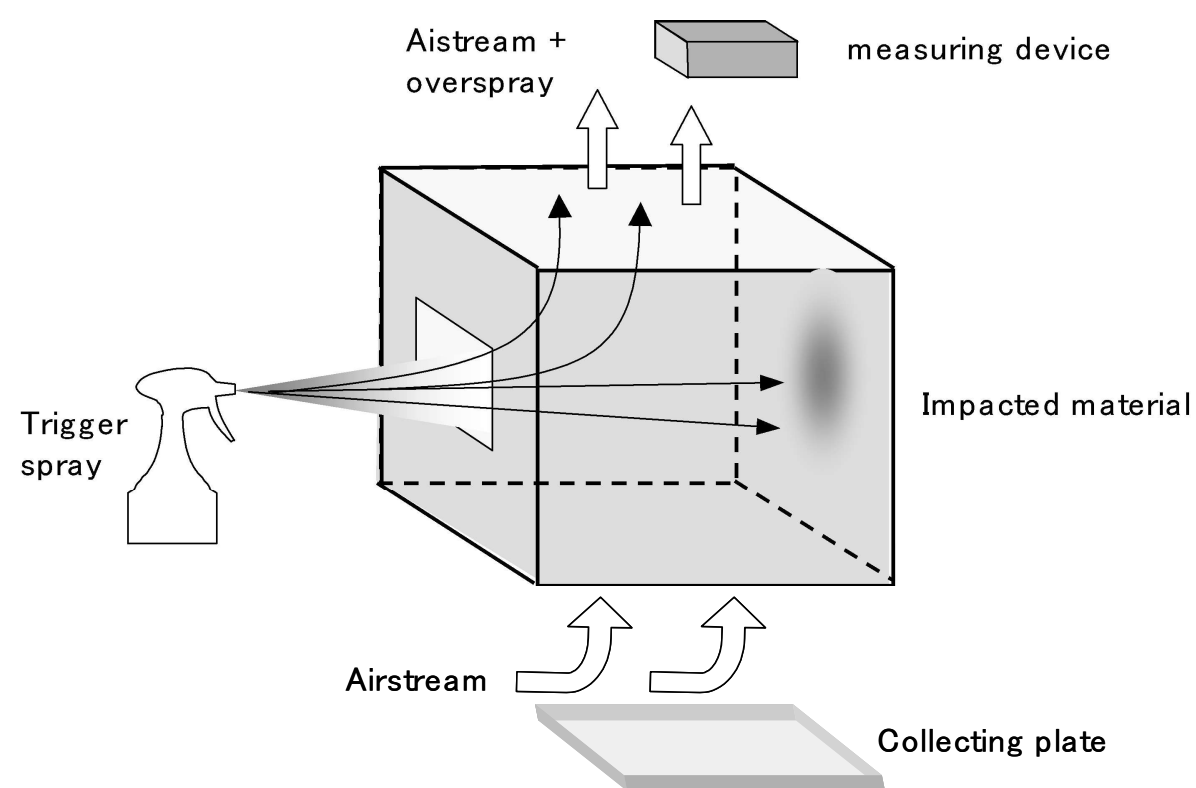

Figure 1

Measure of the impacted material and overspray emission of the trigger spray 


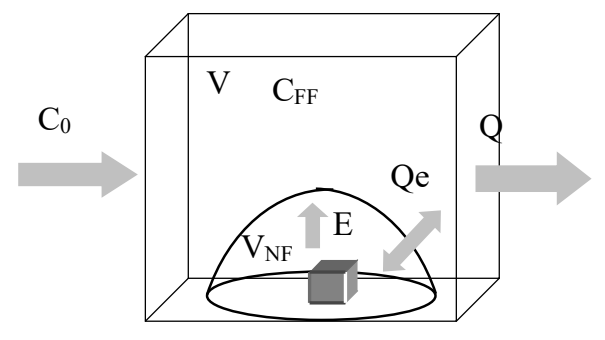

compartment Volume V $\left[\mathrm{m}^{3}\right]$
incoming conc. $C_{\mathrm{o}}\left[\mathrm{mg} / \mathrm{m}^{3}\right]$
Far-field conc. $C_{\mathrm{FF}}\left[\mathrm{mg} / \mathrm{m}^{3}\right]$
Near-Field conc. $C_{\mathrm{NF}}\left[\mathrm{mg} / \mathrm{m}^{3}\right]$
ventilation flow $\mathrm{Q}\left[\mathrm{m}^{3} / \mathrm{s}\right]$
emission coefficient $\mathrm{E}[\mathrm{g} / \mathrm{s}]$
near-field volume $\mathrm{V}_{\mathrm{NF}}\left[\mathrm{m}^{3}\right]$
inter-compartment flow: $\mathrm{Qe}\left[\mathrm{m}^{3} / \mathrm{s}\right]$

Figure 2

Schematic view of the two-compartment model 


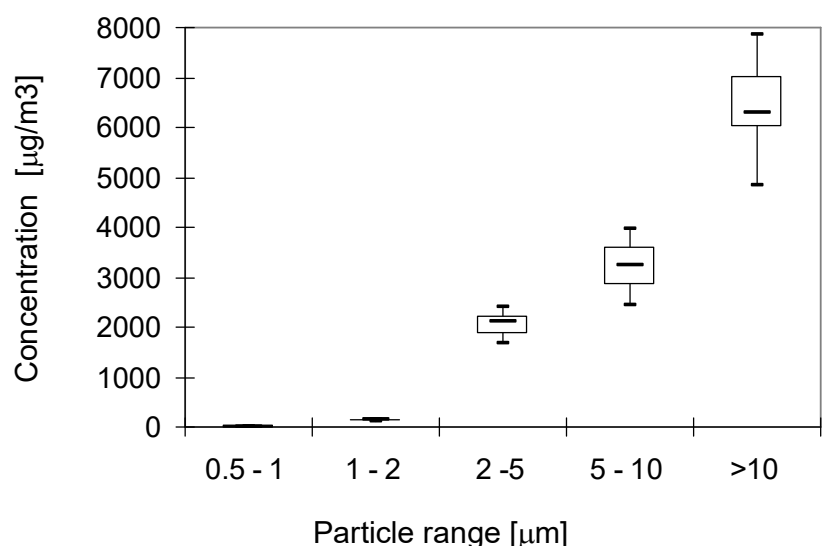

(a)

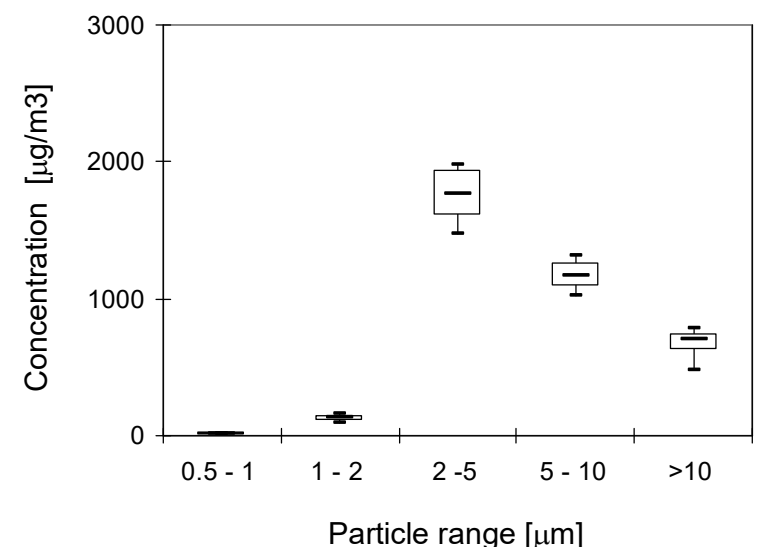

(b)

Figure 3

Particle size distribution in the overspray issued for resin 1 (a) and resin 2 (b). ( $n=10$ measures) 


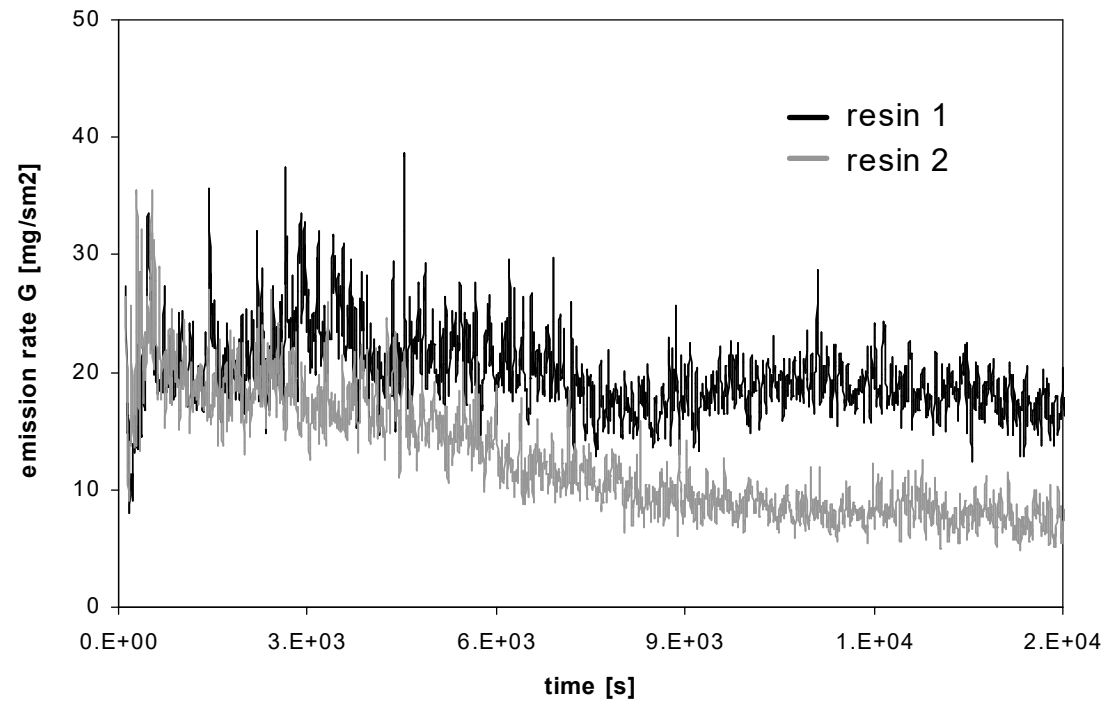

Figure 4

Solvent emission rate from coated surfaces 


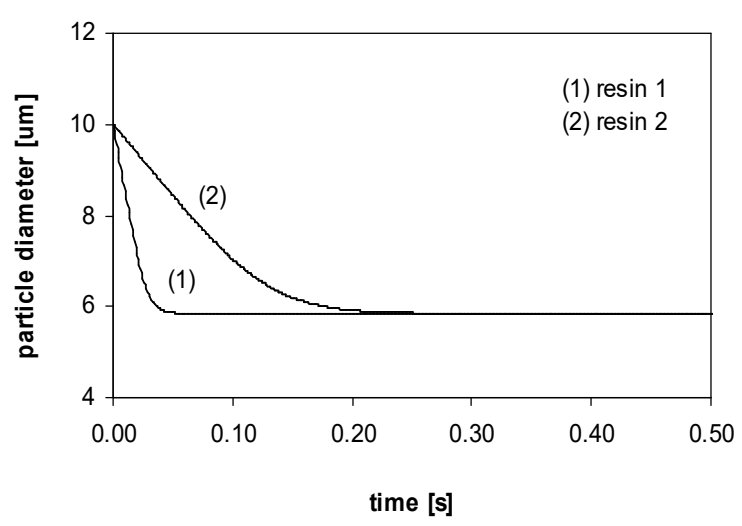

(a) Evaporation of $10 \mu \mathrm{m}$ particles for resin 1 and 2 .

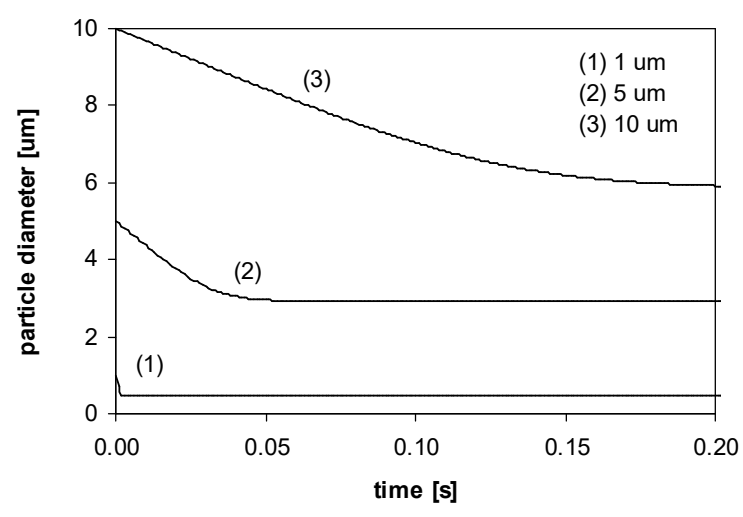

(b) Evaporation of respirable particles for resin 2 .

Figure 5

Evaporation of airborne droplets. 


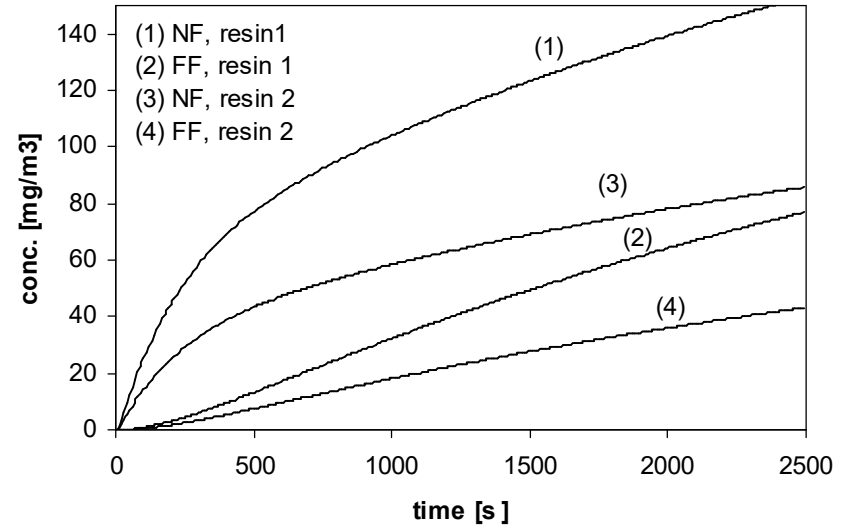

(a) dispersion for resin 1 and 2 into room 2 .

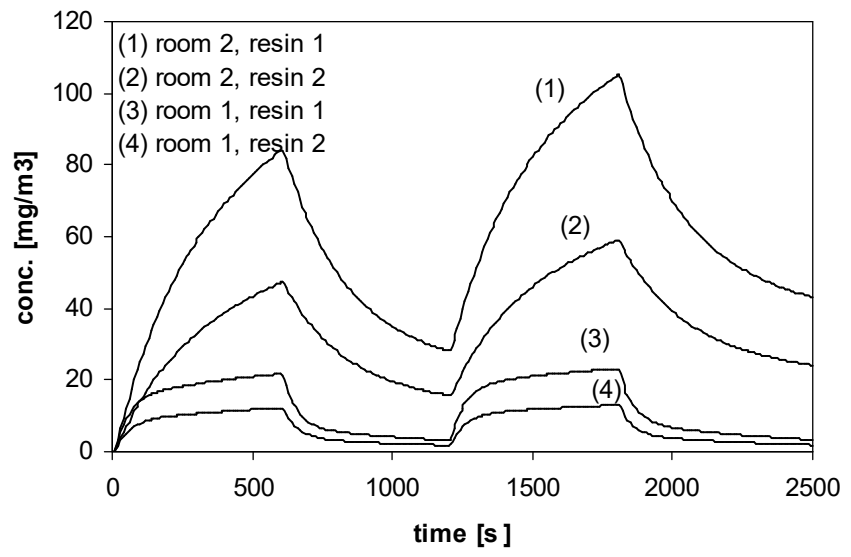

(c) intermittent emission of resin 1 and 2 into room 2 .

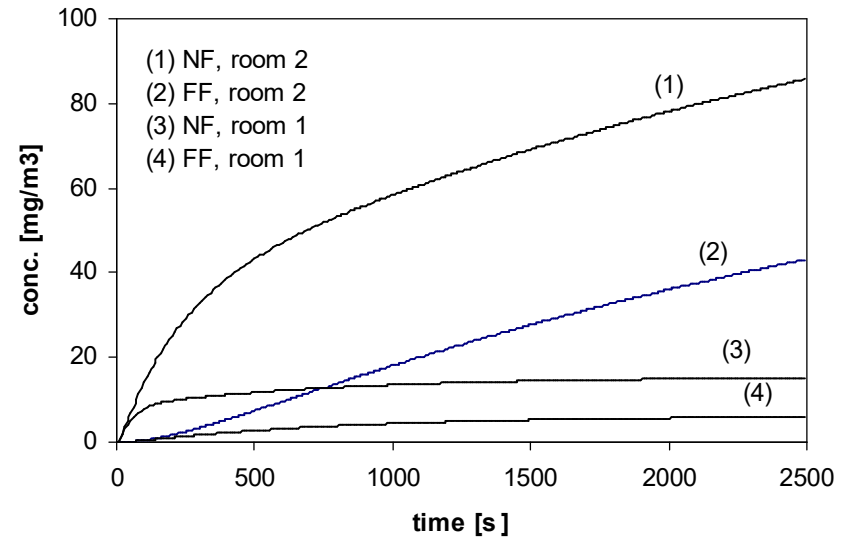

(b) dispersion of resin 2 into room 1 and 2 .

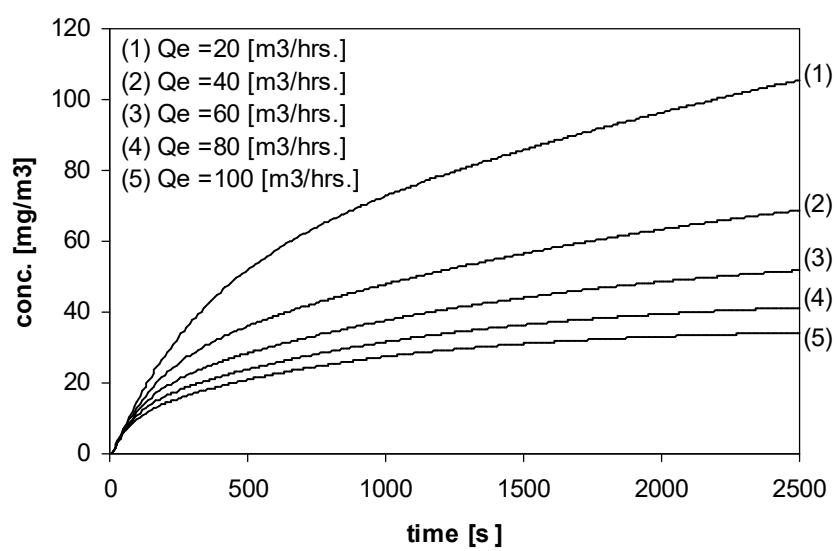

(d) sensitivity to Qe (room 2, resin2)

Figure 6

Overspray concentration evolution calculated with a two-zone model. 


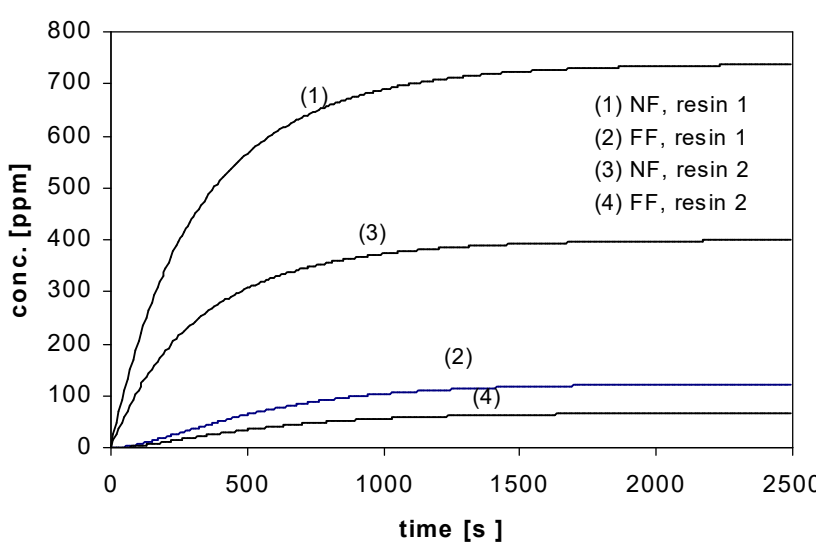

(a) dispersion for resin 1 and 2 into room 2

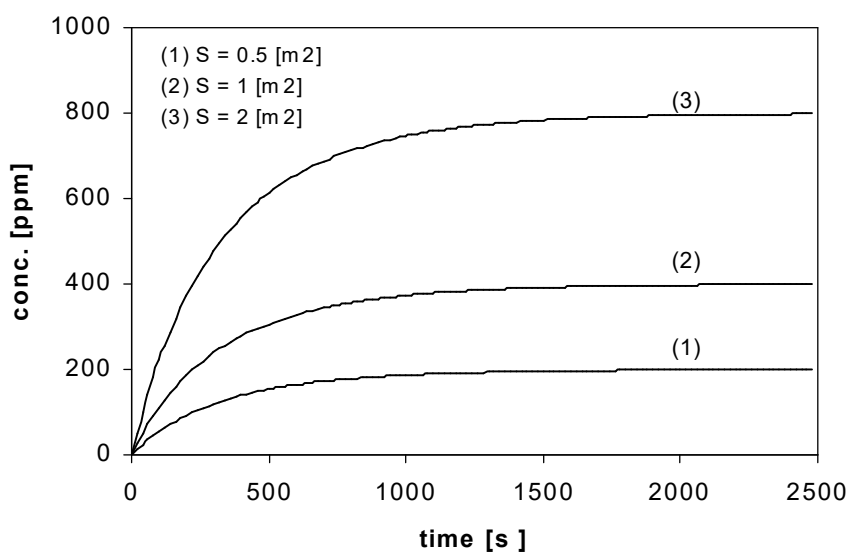

(c) sensitivity to $\mathrm{S}$ (room 2, resin2)

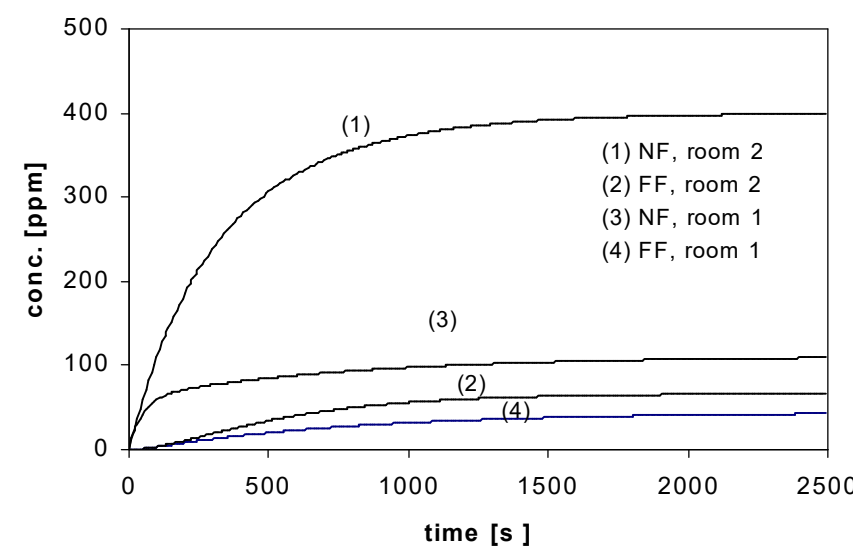

(b) dispersion of resin 2 into room 1 and 2

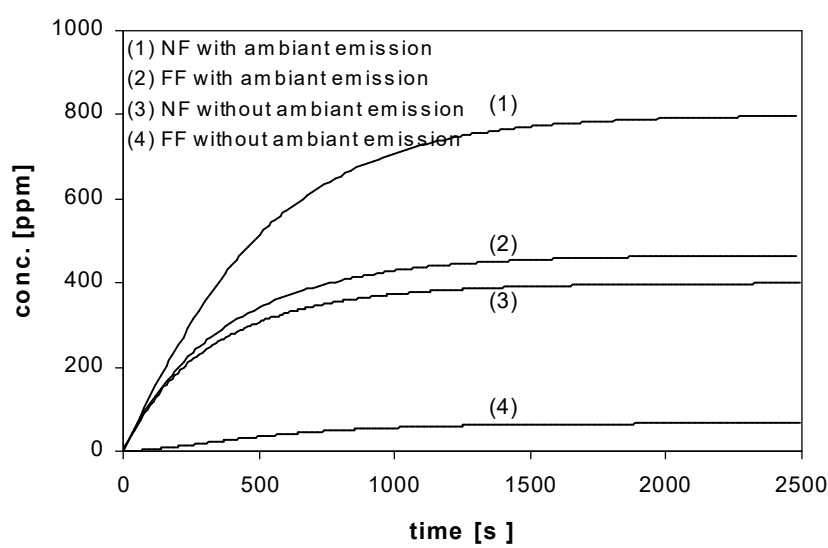

(d) with and without emission in the far-field

Figure 7

Solvent concentration evolution calculated with a two-zone model 